\title{
Comparative analysis of single versus double intrauterine insemination
}

\author{
Pratima T. Wagh*
}

Department of Obstetrics and Gynecology, Lilavati Hospital and Research Centre, Bandra (West), Mumbai, Maharashtra, India

Received: 21 October 2016

Revised: 23 October 2016

Accepted: 25 October 2016

\section{*Correspondence:}

Dr. Pratima T. Wagh,

E-mail: pratimawagh22@gmail.com

Copyright: () the author(s), publisher and licensee Medip Academy. This is an open-access article distributed under the terms of the Creative Commons Attribution Non-Commercial License, which permits unrestricted non-commercial use, distribution, and reproduction in any medium, provided the original work is properly cited.

\begin{abstract}
Background: IUI is simple, less costly compared to other reproductive techniques but there is discrepancy even in recent studies about the timing of IUI. Compared with single IUI, a second consecutive IUI adds significantly to cost and psychological burden, making it important to confirm its beneficial effects before recommending this procedure on large scale.

Methods: It is hospital based retrospective study, carried out in a private tertiary care hospital of Mumbai over a period of one year. All cases who had already undergone IUI during the given time frame were consecutively selected as per inclusion \& exclusion criteria for the study. We considered different factors in the study group and their effect on the fertility of the couples.

Results: Out of 150 couples, $119(79.3 \%)$ underwent single IUI during the study and $31(20.7 \%)$ underwent double IUI. $72.67 \%$ couple had infertility for $1-3$ years, $90.67 \%$ primary and $9.33 \%$ secondary infertility, $51.3 \%$ women with normal BMI and $77.8 \%$ with PCOS, $29.4 \%$ of single IUI and $32.3 \%$ of double IUI group had positive pregnancies. As only the couples with normal semen analysis were selected, male factors like age and co-morbidities in the male did not show any significant effect on the fertility in the study groups.

Conclusions: Women with younger age, normal BMI and with PCOS have better chances of pregnancy in first 3 attempts of IUI with controlled ovarian stimulation and there is no difference in the pregnancy rates by using either double IUI or single IUI in the treatment of sub fertile couple.
\end{abstract}

Keywords: HCG, Infertility, Intrauterine insemination

\section{INTRODUCTION}

Infertility is a global issue and it has become a major healthcare concern.

Infertility is generally defined as the inability to conceive despite regular and unprotected intercourse for 1 year. The term Subfertility is used to describe women or couples who are not sterile but exhibit decreased reproductive efficiency.

One in every four couples in developing countries is affected by infertility. As per WHO (World Health
Organization) 2004, 60- 80 million couples are suffering from infertility globally every year, out of which 15- 20 million are in India alone.

Fertility rate in India has been declining; it was 2.7 as per 2009 survey.

The probability of achieving a live birth without treatment decreases with increasing age and duration of subfertility. The probability of pregnancy without treatment decreases by about $5 \%$ for each added year of female partner age and by $15-25 \%$ for each added year of subfertility. ${ }^{1}$ Most of the spontaneous pregnancies occur 
within first 3 years; thereafter, the prognosis for success without treatment is relatively poor.

Taking into account that the possibility of spontaneous pregnancy is $2 \%$ without any therapy, assisted reproduction is the next logical step to increase the possibility of pregnancy. ${ }^{2}$

Intrauterine insemination (IUI) is an assisted reproductive technique which involves the deposition of a processed semen sample in the uterine cavity. IUI is based on the natural ability of the sperm to fertilize an egg in female reproductive tract.

However many aspects that could optimize the rate of success of IUI remain to be defined. Among the debated issues is the correct timing of insemination, the impact of follicle rupture at the time of IUI and the number of insemination per cycle.

No difference has been detected among the timing of IUI, as shown by recent Cochrane review. ${ }^{3}$ The timing of IUI in the majority of published studies is 32 to 36 hours following HCG administration. As regards the impact of the number of inseminations per cycle pregnancy rate (CPR), the majority of available studies have reported no significant difference between single and double IUI, while few studies have suggested better cycle outcome with double IUI.

Although few studies showed that superovulation with double IUI had better pregnancy rates than with a single application, recent studies found that ovarian stimulation with double insemination has not increased pregnancy rates.

Thus some authors have suggested that increasing the number of inseminations per cycle from one to two may increase the probability of conception. There is discrepancy even in recent studies. Compared with single IUI, a second consecutive IUI adds significantly to cost and psychological burden, making it important to confirm its beneficial effects before recommending this procedure on large scale.

\section{METHODS}

The present study is hospital based retrospective study, carried out in a private tertiary care hospital of Mumbai over a period of one year.

All cases that had already undergone IUI during the given time frame were consecutively selected as per inclusion $\&$ exclusion criteria for the study.

The study was carried out after the approval of the Hospital Ethics Committee.

All the records of couples with primary or secondary infertility who came to the hospital for treatment and who underwent IUI and fitting into inclusion criteria were reviewed.

\section{Inclusion criteria}

1. Age group: $\leq 35$ years

2. Infertility equal to or more than one year (primary or secondary)

3. At least one patent fallopian tube on hysterosalpingography (HSG)

4. Normal semen analysis

\section{Exclusion criteria}

1. Age $>35$ years

2. Tubal factor infertility

3. Abnormal endometrial cavity (as seen on HSG)

4. Male factor infertility

The intention was to postulate the better modality between the two procedures and modify the treatment plan for better management of sub fertile couples depending upon the results of the study.

Total number of couples who passed inclusion criteria was 150 .

As the study was retrospective, allocation of patient to single or double IUI were carried out by the physician as per medical expertise and no special criteria were applied for choosing a particular type of IUI (single or double) in a particular patient.

The example of the standard hospital protocol usually followed in each couple for the procedure of IUI is as mentioned below:

1. History of the couple as per proforma.

2. General, physical and gynaecological examination.

3. Baseline ultrasonography to assess ovaries (antral follicles/cysts) on day 1 or day 2 of menses.

4. Tablet clomiphene citrate $100 \mathrm{mg}$ at bedtime from day 2 to day 6 of cycle for 5 days. ${ }^{4}$

5. Injection recombinant FSH 100 units on day 7, 8, $9^{\text {th }}$ of cycle. ${ }^{5}$

6. Injection HCG 10,000 IU IM when dominant follicle is more than $18-20 \mathrm{~mm}$ size.

7. (Dose of tablet clomiphene citrate, Inj. FSH and Inj. HCG modified according to patient's BMI, PCOS status and follicular response as shown on ultrasonography).

8. Informed and written consent for intrauterine insemination.

9. Sperm preparation (partner's) by standardized sperm preparation techniques. Swim up technique preferred for all patients.

10. Single (after 36 hours of inj. HCG) or double (after 12 hours and 36 hours of inj. HCG) intrauterine insemination under all aseptic precautions.

11. Pregnancy test on day 14 by serum beta HCG levels. 


\section{RESULTS}

Table 1: Factors affecting clinical pregnancy rate.

\begin{tabular}{|c|c|c|c|c|c|c|}
\hline & Groups & Number (n) & $\begin{array}{l}\text { Positive } \\
\text { pregnancy }\end{array}$ & Percentage (\%) & P value & $\begin{array}{l}\text { Difference of } \\
\text { significance }\end{array}$ \\
\hline \multirow{3}{*}{$\begin{array}{l}\text { Age of female } \\
\text { (years) }\end{array}$} & $<25$ & 51 & 19 & 42.2 & \multirow{3}{*}{0.013} & \multirow{3}{*}{$\mathrm{S}$} \\
\hline & $26-30$ & 68 & 22 & 48.8 & & \\
\hline & $31-35$ & 31 & 4 & 8.8 & & \\
\hline \multirow{2}{*}{$\begin{array}{l}\text { Type of } \\
\text { infertility }\end{array}$} & Primary & 136 & 40 & 88.9 & \multirow{2}{*}{0.624} & \multirow{2}{*}{ NS } \\
\hline & secondary & 14 & 5 & 11.1 & & \\
\hline \multirow{3}{*}{ BMI $\left(\mathrm{kg} / \mathrm{m}^{2}\right)$} & Upto 24.99 & 77 & 29 & 64.4 & \multirow{3}{*}{0.045} & \multirow{3}{*}{$\mathrm{S}$} \\
\hline & $25-30$ & 43 & 12 & 26.7 & & \\
\hline & $>30$ & 30 & 4 & 8.9 & & \\
\hline \multirow{2}{*}{ PCOS } & Yes & 55 & 35 & 77.8 & \multirow{2}{*}{0.000} & \multirow{2}{*}{$\mathrm{S}$} \\
\hline & No & 95 & 10 & 22.2 & & \\
\hline \multirow{2}{*}{ Type of IUI } & Single & 119 & 35 & 29.4 & \multirow{2}{*}{0.758} & \multirow{2}{*}{ NS } \\
\hline & Double & 31 & 10 & 32.3 & & \\
\hline \multirow{2}{*}{ Number of IUI } & Upto 3 & 126 & 44 & 97.8 & \multirow{2}{*}{0.002} & \multirow{2}{*}{$\mathrm{S}$} \\
\hline & $\geq 4$ & 24 & 1 & 2.2 & & \\
\hline \multirow{2}{*}{ Tubal patency } & Unilateral & 19 & 4 & 8.9 & \multirow{2}{*}{0.069} & \multirow{2}{*}{$\mathrm{NS}$} \\
\hline & Bilateral & 131 & 41 & 91.1 & & \\
\hline
\end{tabular}

(S- significant, NS- not significant)

Table 2: Duration of infertility and clinical pregnancy rate.

\begin{tabular}{|llllllll|}
\hline Duration of infertility (yrs) & $\mathbf{N}$ & Mean & Std. Deviation & Median & IQR & Mann-Whitney Test P Value \\
\hline Positive & 45 & 2.76 & 0.688 & 2.50 & 1.000 & -0.341 & 0.733 \\
\hline Negative & 105 & 3.07 & 1.342 & 3.00 & 1.750 & Difference not significant \\
\hline
\end{tabular}

We included male patients with normal semen analysis only as per WHO guidelines 2010. We used swim up technique for sperm washing for all the patients.

Amongst females, 51(34\%) were in $\leq 25$ years of age group, $68(45.33 \%)$ were in 26 to 30 years of age group and $31(20.67 \%)$ were 31 to 35 years of age. We included patients equal to or less than 35 years of age.

$109(72.67 \%)$ couples had infertility for 1-3 years, 39 $(26 \%)$ of couples had infertility for $>3-6$ years and 2 $(1.33 \%)$ couples had more than 6 years of infertility.

Out of 150 patients of our study $136(90.67 \%)$ had primary infertility and remaining i.e. $14(9.33 \%)$ patients had secondary infertility.

Out of 150 women, majority i.e. $77(51.3 \%)$ women had BMI (body mass index) in the normal range i.e. $\leq 24.99$ $\mathrm{kg} / \mathrm{m}^{2}, 43(28.7 \%)$ women were overweight with BMI in the range of 25 to $30 \mathrm{~kg} / \mathrm{m}^{2}$ and $30(20 \%)$ were obese with BMI more than $30 \mathrm{~kg} / \mathrm{m}^{2}$.

In our study 3 (2\%) women were diabetic, 5 (3.33\%) had endometriosis as diagnosed by laparoscopy and 55 (36.67\%) women had PCOS, whereas 87 (58\%) women had no associated co-morbid conditions; most probably unexplained infertility.

Among the study population 10 males were diabetic and 2 were hypertensive.

Before the procedure of IUI, all female patients were subjected to hysterosalpingography (HSG) to determine the state of tubal patency. Out of 150 patients, $19(12.7 \%)$ had unilateral tubal block and remaining i.e. 131 (87.3\%) patients had normal bilaterally patent tubes.

Out of 150 patients, 126 patients had history of previous 1 to 3 IUI cycles done in the past and 24patients had more than or equal to 4 IUI cycles in the past.

Out of 150 couples, $119(79.3 \%)$ underwent single IUI during the study and $31(20.7 \%)$ underwent double IUI.

In our study the overall pregnancy rate per couple was $30 \%$ i.e. 45 out of 150 patients conceived.

\section{DISCUSSION}

In 2014 Laka Dinelli in a retrospective study suggested that women with secondary infertility have significantly 
better pregnancy rates after IUI than women with primary infertility i.e. $16.7 \%$ versus $13.5 \%(\mathrm{p}=0.04){ }^{6}$

In our study, out of 150 couples, 136 had primary infertility and 14 couples had secondary infertility. Out of total 45 patients with positive pregnancy results, 40 $(88.9 \%)$ belonged to primary infertility group and 5 $(11.1 \%)$ were from secondary infertility group. But the association was not statistically significant $(\mathrm{p}>0.05)$.

In a study, in 2012 , by Hao Huang et al, 169 women were in 20-29 years of age group, 306 were in 30-34 years and 189 were $35-40$ years of age and the pregnancy rates per couple were $21.9 \%, 19 \%, 20.6 \%$, respectively $(p=0.734) .^{7}$ Thus there was no significant difference in pregnancy rates in different age group of women in this study.

In our study, females belonged to different age groups, 51 $(34 \%)$ were in $\leq 25$ years of age group, $68(45.33 \%)$ were in 26 to 30 years of age group and $31(20.67 \%)$ were 31 to 35 years of age. Pregnancy rates were $42.2 \%(n=19)$, $48.8 \%(n=22), 8.8 \%(n=4)$ respectively. Mean age in women with positive pregnancy results was 26.2 years. Significantly better positive pregnancy results were found in women with younger age group $(\mathrm{p}=0.009)$.

In the study by Hao Huang, 149 couples had infertility for 12 to 23 months, 166 couples for 24 to 35 months and 349 couples were infertile for more than 36 months. ${ }^{7}$ Pregnancy rates were $26.2 \%, 19.9 \%$ and $17.8 \%$, respectively $(\mathrm{p}=0.1)$. Thus they concluded that duration of infertility does not affect pregnancy rates.

In our study, median duration of infertility was 2.5 years in the group with positive pregnancy results $(n=45)$ and that in the couples with negative pregnancy results $(n=105)$ was 3 years. The association was not statistically significant $(\mathrm{p}=0.733)$. Suggesting that duration of infertility did not affect the pregnancy rates in our study.

A retrospective chart review by Randi H. Goldman included 1438 women, divided into BMI groups of $<25$, $25-30,30-35$ and $>35 \mathrm{~kg} / \mathrm{m}^{2}$, they found that positive pregnancies were found in the group with mean BMI of $24.9 \pm 5 \mathrm{~kg} / \mathrm{m}^{2} \quad(\mathrm{p}<0.01)$ which was statistically significant. $^{8}$

In our study, out of 150 women, $77(51.3 \%)$ had BMI $\leq 24.99 \mathrm{~kg} / \mathrm{m}^{2}, 43(28.7 \%)$ had BMI of 25 to $30 \mathrm{~kg} / \mathrm{m}^{2}$ and $30(20 \%)$ women had BMI of $>30 \mathrm{~kg} / \mathrm{m}^{2}$, pregnancy were $29(64.4 \%), 12(26.7 \%)$ and $4(8.9 \%)$ respectively $(\mathrm{p}=0.045)$. This shows that woman with lower BMI had significantly better pregnancy rates as compared to overweight or obese women.

A retrospective observational study in 2005 by Sulit et al, there were 44 patients with PCOS and 242 were non PCOS. ${ }^{9}$ Clinical pregnancy rates were $40.9 \%$ and $22.73 \%$, respectively $(\mathrm{p}=0.01)$. Thus PCOS patients have significantly higher pregnancy rates than non PCOS patients.

In our study, out of 150 women, 55 (36.67\%) women had PCOS. Out of 45 women with positive pregnancy results, $35(77.8 \%)$ were PCOS and $10(22.2 \%)$ were non-PCOS $(\mathrm{p}=0)$. Thus our study showed that women with PCOS had significantly better pregnancy rates compared to nonPCOS patients.

In a study conducted by Hill MJ et al, in 2013, the clinical pregnancy rates were similar between the two groups (single IUI: $16.4 \%$, double IUI: $13.6 \%, \mathrm{P}=0.07) .{ }^{10}$

A meta-analysis by Apostolos Zavos, et al included five trials involving 1125 IUI cycles. ${ }^{11}$ There was a two-fold increase in pregnancies in double IUI group compared with single IUI group $(\mathrm{P}<0.03)$. Sensitivity analysis, excluding a large trial, revealed higher pregnancy rates among double IUI cycles but without statistical significance $(\mathrm{P}=0.20)$.

Cochrane database involved six studies with 1785 women. ${ }^{12}$ They found that double IUI gives rise to higher pregnancy rates. (peto odds ratio $1.8,95 \%$ confidence interval, 1.4 to 2.4$)$.

In our study, out of 150 patients, 119 patients underwent single IUI and 31 patients underwent double IUI during the study. Amongst the 119 of single IUI group positive pregnancies were 35 (29.4\%) and out of 31 of double IUI group $10(32.3 \%)$ were positive. The association was found to be non-significant ( $\mathrm{p}>0.05$ ).

The retrospective study by Patel D et al, the pregnancy rate in cycle $1-3(36.1 \%)$ was significantly higher than in cycles $4-6(21.6 \%)(\mathrm{P}<0.0001) .{ }^{13}$ Thus they concluded that pregnancy rates significantly decreases with increasing numbers of IUI cycles.

In our study, $126(84 \%)$ patients underwent $\leq 3$ IUI cycles in the past and $24(16 \%)$ had history of $\geq 4$ IUI cycles done in the past. Out of total 45 conceived patients, 44 (97.8\%) belonged to the first group and 1 (2.2\%) was from the second group $(\mathrm{p}=0.002)$. Hence it was found out in our study that pregnancy rate reduces beyond $3^{\text {rd }}$ IUI cycle.

In our study, out of 150 women, 19 (12.7\%) had unilateral tubal block and $131(87.3 \%)$ had bilaterally patent tubes. Out of 45 patients who conceived with IUI, $4(8.9 \%)$ were from unilateral tubal block group and 41 $(91.9 \%)$ were from bilaterally patent tubes group $(p=0.069)$. Thus patients with bilaterally patent tubes had better pregnancy rates but the association was not statistically significant.

In our study, out of 150 women only 5 had endometriosis and 3 had diabetes, hence effect of these conditions on fertility could not be studied in the population group. As 
only the couples with normal semen analysis were included in the study, age of male and co-morbidities in male had no significant effect on clinical the pregnancy rate.

\section{CONCLUSION}

From our retrospective study carried out at a private tertiary care hospital, it can be concluded that:

There is no difference in the pregnancy rates by using either double IUI or single IUI in the treatment of sub fertile couple.

Our study also concludes that women with younger age, normal BMI and with PCOS have better chances of pregnancy in first 3 attempts of IUI with controlled ovarian stimulation.

Pregnancy rates in women with bilaterally patent fallopian tubes are higher than women with unilaterally blocked tubes but the association in our study was not statistically proven.

We found that IUI remains the first line of treatment in patients with younger age group, at least one patent fallopian tube and normal semen analysis.

Funding: No funding sources Conflict of interest: None declared

Ethical approval: The study was approved by the Institutional Ethics Committee

\section{REFERENCES}

1. Fritz MA, Speroff L. Textbook of clinical gynecologic endocrinology and infertility, $8^{\text {Th }}$ edition; 2012;27:1158.

2. Tournaye H. Male factor infertility and ART. Asian J Androl. 2012;14:103-8.

3. Contineau AEP, Janssen MJ, COhlen BJ, Syncronised approach for IUI in sub fertile couples. Cochrane database syst rev. 2010.
4. Use of clomiphene citrate in infertile women: a committee opinion Practice Committee of the American Society for Reproductive Medicine. Fertil Steril. 2013 Aug;100(2):341-8.

5. Marc A. Fritz, Speroff L. Textbook of clinical gynecologic endocrinology and infertility, $8^{\text {Th }}$ edition; 2012;7:261.

6. Dinelli L. Prognosis factors of pregnancy after intrauterine insemination with the husband's sperm: conclusions of an analysis of 2,019 cycles. Fertil Steril. 2014;101:994-1000.

7. Huang H. Predictors of pregnancy and live birth after insemination in couples with unexplained or malefactor infertility. Fertil steril. 2012;97:959-67.

8. Goldman RH. Patient-specific predictions of outcome after gonadotropin ovulation induction/intrauterine insemination. Fartil steril. 2014;101:1649-55.

9. Sulit MT. Comparing pregnancy outcomes of PCOS versus non PCOS (ovulation enhanced) patients who underwent Clomiphene citrate/Intrauterine insemination cycles. Fertil steril. 2005;84:S431-2.

10. Hill MJ, Richter KS, Zarek SM, DeCherney AH, Osheroff JE, Levens ED. Single and double donor sperm intrauterine insemination cycles for male factor infertility: does double IUI increase clinical pregnancy rates? Fertility and sterility. 2013.

11. Zavos A. Double versus single homologous intrauterine insemination for male factor infertility: a systematic review and meta-analysis. Asian J Androl. 2013 July;15(4):533-8.

12. Cantineau AEP, Heineman MJ, Cohlen BJ. Single versus double intrauterine insemination (IUI) in stimulated cycles for sub fertile couples. Cochrane database of systematic review. 2003;1:CD003854.

13. Patel D. IUI treatment beyond 3 cycles is not at exercise in futility, especially in older women. Fertil steril. 2013;100(3):S467.

Cite this article as: Wagh PT. Comparative analysis of single versus double intrauterine insemination. Int J Reprod Contracept Obstet Gynecol 2016;5:4151-5. 